DOI: 10.12731/2077-1770-2020-6-73-84

УДК 811.11-112

\title{
ТРАГЕДИЯ И. ГЕТЕ «ФАУСТ» В ЧУВАШСКОЙ ЛИТЕРАТУРЕ: ЛИНГВИСТИЧЕСКИЕ ОСОБЕННОСТИ ПЕРЕВОДА НА ЧУВАШСКИЙ ЯЗЫК
}

\section{Емельянова М.В., Кузнецова Т.Н.}

Цель. Статья посвящена лингвистическим особенностям перевода трагедии И. Гете «Фауст» на чувашский язык, выполненном чувашским языковедом и переводчиком Н.А. Андреевым-Урхи. Проводится сравнительно-сопоставительный анализ перевода и оригинала, определяется качество перевода произведения. Цель исследования заключается в комплексном анализе перевода трагедии И. Гете «Фауст» на чувашский язык, рассмотрении лингвистических особенностей перевода произведения.

Материалы и методы. Материалом исследования послужили лексические единицы, крылатые выражения, пословицы и поговорки, встречающиеся в произведении И. Гете "Фауст». Основными методами данной работы являются сравнительно-сопоставительный и лингвистический.

Результаты. Анализ рассмотренных лингвистических особенностей перевода трагедии И. Гете «Фауст» доказывает, что переводчик подбирал лексические соответствия понятные для чувашского народа, употреблял в переводе живую диалектную речь, т.е. диалект верховых чувашей, что делает данное произведение более близким и родным для чувашского читателя.

Область применения результатов. Полученные результаты могут найти свое применение в учебных курсах по общему и сравнительному языкознанию, типологии языков, теории художественного перевода, а также на практических занятиях по иностранному языку. 
Ключевые слова: перевод; сравнительно-сопоставительный анализ; текст оригинала; язык перевода; лингвистические особенности; диалектизмы; крылатые выражения; пословицы; поговорки.

\section{GOETHE'S TRAGEDY FAUST IN CHUVASH LITERATURE: LINGUISTIC PECULIARITIES OF TRANSLATION INTO CHUVASH}

\section{Emelianova M.V., Kuznetsova T.N.}

Purpose. The article is devoted to the linguistic peculiarities of the translation of Goethe's tragedy Faust into Chuvash by the Chuvash linguist and translator N.A. Andreev-Urhi. A comparative analysis of the translation and the original is carried out, along with evaluation of the translation quality. The purpose of the research is conducting a complex analysis of translation of Goethe's tragedy Faust into Chuvash, including consideration of the linguistic peculiarities of the translation.

Materials and methods. The research material is lexical items, winged expressions, proverbs and sayings of Goethe's work. The main methods of this work are comparative and linguistic ones.

Results. The analysis of considered linguistic peculiarities of the translation of Goethe's tragedy Faust proves that the translator managed to find lexical items being understandable for the Chuvash people and used a living dialect speech in translation, i.e. the dialect of the upper Chuvash people, which makes this work closer and more authentic for the Chuvash reader.

Practical implications. The results of the study can find application in training courses on general and comparative linguistics, language typology, literary translation theory, as well as practical foreign language training.

Keywords: translation; comparative analysis; original text; translation language; linguistic peculiarities; dialectism; winged expression; proverb; saying. 
Издание трагедии И. Гете «Фауст» на чувашском языке сыграло большую роль в культурной жизни чувашского народа, однако многочисленные попытки перевести эту трагедию были безуспешны или не были доведены до конца. Примечательно, что Н.А. Андреев-Урхи приложил все усилия, чтобы приблизить чувашский текст к подлиннику. Благодаря его трудолюбию, таланту, поэтическому дару и владению несколькими языками удалось перевести трагедию И. Гете на чувашский язык, что дает богатый материал для проведения научных исследований в области филологии. Переводные поэтические тексты служат для осуществления сложного коммуникативного процесса: духовного общения между автором и читателями, воспитанными в другой культуре и в лоне другого языка [4]. Важным методом исследования в лингвистике перевода служит сопоставительный анализ перевода, т.е. анализ формы и содержания текста перевода в сопоставлении с формой и содержанием оригинала [2].

В чувашском варианте трагедии И.В. Гете «Фауст» часто встречаются диалектизмы, которые подчеркивают специфику разговорной речи какого-нибудь определенного народа, проживающего на территории Чувашской республики.

Лексические диалектизмы - эквиваленты слов, используемые жителями конкретной местности [3]:

1) минтер (подушка) - с̧ытар (диал.):

Erst senkt sein Haupt aufs kühle Polster nieder-

Пус̧не чӗп-чӗр с̧ытар с̧ине хурсамӑр

(Его склоните нежно к изголовью);

2) кӱршӗ (сосед) - пускил (диал.):

Herr Nachbar, ja! -

С̧апла, пускилём

(Так, так, сосед!);

3) аслашшӗ (дедушка) - мас̧ак (диал.):

Dem Ahnherrn fromm die welke Hand geküßt-

Масуакӗн типӗ аллине вӑл чуптунӑ

(Сухую руку деда цуеловала); 
4) иккен (оказывается) - нихак (диал.):

Das Spionieren, scheints, ist deine Lust. -

Ку вӑрттай шаириласси -

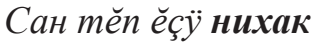

(Шиионство, видно, страсть твоя?).

Грамматические диалектизмы - это слова, образованные с помощью суффиксов, которые не существуют в литературном языке [3]:

1) пӗлетӗп (знаю) - пӗлеп (диал.):

Zwar weiß ich viel, doch möchte ich alles wissen. -

Нумай пӗлеп, татах пӗлес килет

(Хоть много знаю я, но все хотел бы знать);

2) килес̧с̧ӗ (идут) - килес̧ (диал.):

Weh! Weh! Sie kommen. Bittrer Tod! -

Килес̧! с̧итет вилес самант!

(Иуут! Настал час смертный мой!);

Он от ичепей тебя освободит);

3) мӗншӗн (почему) - ма-ке (диал.):

Was hilft es, fliehn? Sie lauern doch mir auf.

Ма-ке тарас? Мана кетет хурал унтах... -

(Зачем бежать? Меня там стража ждет...);

Laß mich! Nein, ich leide keine Gewalt!

Ма-ке вӑйпах? Ан тив манна!

(К чему насилье? О, оставь мою волю!);

4) хӑвӑн (свой) - ху (диал.):

Nun gut, es sei dir überlassen!

Zieh diesen Geist von seinem Urquell ab-

Сана ирӗк паратӑп пётёмпе:

Ил ун чунне ху аллуна

(Тебе позволено: иди

И завладай его душою).

В вышеназванных примерах наблюдается применение суффиксов, окончаний, нарушающих норму чувашского литературного языка: сокращение слов, отсутствие в словах гласной или нескольких букв можно часто заметить в разговорной речи. 
Примеры диалектизмов, приведенные Н.А. Андреевым-Урхи на языке перевода, показывают, что здесь встречается диалект верховых чувашей, характерный для жителей Аликовского района Чувашской республики. Жители других районов республики (низовые чуваши), несмотря на диалектические особенности, понимают содержание данного произведения. Диалект не меняет содержание и смысл произведения, а раскрывает особенности разговорной речи жителей конкретной территории.

В трагедии «Фауст» можно заметить много крылатых выражений, пословиц, поговорок, которые могут заставить задуматься любого переводчика.

Фраза «Остановись, мгновенье, ты прекрасно!» (Werd ich zum Augenblicke sagen: Verweile doch! Du bist so schön!), ставшая крылатой, появилось благодаря произведению И. Гете «Фауст». Многие люди слышали, вспоминали ее в какой-либо ситуации, в общественной жизни или литературе.

При рассмотрении переводов данного выражения на русском и чувашском языках следует отметить, что Э. Губер, А. Фет, А. Соколовский, а также чувашский переводчик Н.А. Андреев-Урхи эквивалентом глагола verweilen (остановиться, пребывать) выбрали остановись, чарӑнсам (чув.). Переводчик Н. Холодковский после глагола продлись добавляет постой для обозначения временного приостановления. В чувашском переводе также используется слово тӑхта (постой, подожди), которое показывает задержку в движении. Остальные переводчики применяют следующие варианты перевода: помедли, продлись, не уходи, останься и др.

И если я скажу мгновенью:

Тебе я рад! остановись! (Э. Губер, 1838)

Когда усльишишь ты хоть раз,

Что я скажу: «помедли час,

Прекрасен тыл, постой». (А. Струговщиков, 1843)

И когда мгновенью я скажу:

«Остановись! Прекрасно ты!!» (А. Фет, 1889)

Если я скажу когда-нибудь пришедшему мгновению: 
«Остановись! - ты так прекрасно!» (А. Соколовский, 1902)

Когда воскликнуя: «Мгновенье,

Прекрасно ты, продлись, постой!» (Н. Холодковский, 1939)

Едва я миг отдельный возвеличу,

Вскричав, «Мгновение, повремени!» (Б. Пастернак, 1955)

Иртсе пыран шух вӑхӑта:

«Самант, илемлӗ эсӗ, чарӑнсам, тӑхта!»

Вара эп калӑттӑм саманта:

Ытла илемлӗ эсӗ, тӑсӑлсам, тӑхта! (Н.А. Андреев-Урхи).

Сравнительно-сопоставительный анализ пословиц и поговорок на разных языках показывает, что эти народы имеют много общего, и это способствует их лучшему взаимопониманию и сближению. Следует подчеркнуть, что многие немецкие и чувашские пословицы и поговорки многозначны. Многозначность делает их трудными для толкования и сравнения, поэтому трудности при переводе немецких пословиц и поговорок возникают всегда. Если даже учитывать все особенности языков, сложно переводить на другой язык то, что считается частью культуры определенного народа [9]. Для иноязычного читателя пословица кажется чем-то новым, поэтому смысл не всегда раскрывается полностью. Значит, для того, чтобы носитель другого языка понял значение пословицы, нужно подобрать эквивалент на языке перевода:

Ein Sprichwort sagt: Ein eigner Herd,

Ein braves Weib sind Gold und Perlen wert. -

Ват с̧ын с̧апла каланӑ: «Ӑшӑ пӱрт тата

Ыр арӑм ылтӑнпа чӑн ахахран паха»

(Пословица гласит: жена своя и кров

Дороже всех на свете нам даров).

Все эти пословицы на трех языках имеют общий смысл, это можно проследить при сопоставительном анализе: общие имена существительные der Herd - nӱрm (очаг, дом), das Weib - apăм (жена), das Gold - ылтай (золото), die Perle - axax (жемчужина). В русском переводе пословицы слова das Gold - ылтӑн (золото) и die Perle - axax (жемчужина) заменены одним общим именем существительным дар. 
Ein Dienst ist wohl des andern wert. -

Чӑн, с̧ӑкӑрпа тӑвар хире-хирессле

(Что же, за услугу я готов служить);

Alles nach seiner Art. -

Кама кам килецшет

(У всякого свой вкус).

В данных пословицах на немецком и чувашском языках нет общих эквивалентов, их объединяет только общий смысл. Переводчик подобрал соответствующую пословицу на чувашском языке, ссылаясь на смысл переводимой пословицы.

Выражению Ihr habt weiches Holz zu spalten подобрали эквивалент на чувашском языке Утне кура турти, Н. Холодковский перевел С волками жить - по-волчьи выть, а А. Соколовский - Вам придется рубить мягкое дерево. Если рассмотреть все три варианта перевода, то дословным является только перевод А. Соколовского, только у него имеются общие с оригиналом лексические единицы: weiches Holz - мягкое дерево, spalten - pубить.

В выражении Vom Himmel durch die Welt zur Hölle - Çйл пӗлӗтрен с̧ӗр витецр тамӑка (через землю с неба в ад) основными лексическими единицами, сохранившимися на языке перевода, являются Himmel-nӗлӗm (небо), Hölle - тамӑк (ad), а слово die Welt заменено чувашским словом с̧ӗр (земля). Данная лексическая трансформация не меняет значение выражения, т.к. эти слова являются близкими по значению.

Wie Himmelkräfte auf und nieder steigen

Und sich die goldenen Eimer reichen! -

Епле суйлти вӑй-хӑватсем весссе с̧ӥрес̧сеӗ,

Пӗрне-пӗри с̧ут ылтаци куркапа сийлес̧с̧ӗ!

(Как силь вышние в сосудах золотых

Разносят всюду жизнь божественной рукою...)

Словосочетание die goldenen Eimer (золотое ведро) в чувашском переводе заменено ылтӑн курка (золотой кови), лексические единицы ведро и ковш обозначают сосуд для наполнения жидкости, т.е. имеют синонимичное значение. 
Переводчик В.А. Иванов считает трагедию И. Гете «Фауст» педагогическим произведением [8], сопоставляя оригинал с его переводами на русском и чувашском языках, он доказывает это: Гете пытался хотя бы на малом клочке немецкой земли улучшить общественный уклад жизни и сделать его образцом для всей страны, а после этого неудавшегося переустройства ведая делами просвещения в герцогстве. Жизненные переживания, итог шестидесятилетней творческой деятельности, заветные мечты и светлые догадки вложены им в знаменитую трагедию «Фауст». Гетевский Фауст - ученый, искатель истины, герой оптимистической трагедии [1].

O glücklich, wer noch hoffen kann, Aus diesem Meer des Irrtums aufzutauchen! -

Суя пёлӥ ултавёнчен тухма

Кам шанчӑк суухатман - телейлӗ!

(О счастлив тот, кому дана отрада, -

Надежда выбраться из непроглядной тьмыз!).

В названных строках И. Гете восклицает, что знания нужны человеку как воздух. Перевод на чувашский язык отличается введением слова пёлӥ (знание), хотя в немецком и русском текстах оно отсутствует.

В трагедии «Фауст» И. Гёте восхваляет деятельность просветителя и искренне благодарит его: ведь именно он «сеет разумное, доброе, вечное»:

Vor jenem droben steht gebückt,

Der helfen lehrt und Hilfe schickt. -

Кам вёрентет ыр ецс тума с̧ынна,

Пус̧ тайӑnӑр пурте с̧авна.

(Склонитесь лучше перед тем,

Кто учит всех и благ ко всем).

Данные предложения на трех языках представляют собой сложноподчиненные предложения с придаточными изъяснительными, образованные с помощью союзных слов der, кам, кто. Сопоставительный синтаксический анализ показывает, что в чувашском 
предложении придаточная часть стоит на первом месте, а потом идет главное предложение, а в оригинале и русском переводе сохранена одинаковая структура сложноподчиненного предложения: главное предложение, а затем придаточное. Переводчик выбирает наиболее оптимальный для своей индивидуальности способ разрешения проблем и противоречий, которые могут возникнуть в процессе перевода [7].

Действительно, важные изречения И. Гете и их переводы на русский и чувашский языки являются хорошим материалом для образовательных и воспитательных целей. Сопоставительное рассмотрение трагедии «Фауст» с ее переводами дает возможность выделить, какими средствами пользуются переводчики, чтобы точно передать какую-нибудь фразу или образ на языке перевода, чтобы внутренняя жизнь переводного выражения соответствовала внутренней жизни оригинального.

Результаты проведенного анализа доказывают, что при переводе трагедии «Фауст» Н.А. Андреев-Урхи использовал разные способы передачи содержания на языке перевода, в том числе нелитературные слова и формы слов, допуская оправданные контекстом отступления от норм литературного языка. Осознанное ненормативное употребление живой диалектной речи делает данное произведение более близким и родным для чувашского читателя. Проанализированные примеры перевода трагедии «Фауст» подтверждают, что особенность передачи содержания произведения заключается в том, чтобы найти лексические соответствия, наиболее популярные и близкие для чувашского народа.

\section{Список литературы}

1. Иванов В.А. Трагедия «Фауст» как педагогическое произведение в сопоставлении ее с переводами на русский и чувашский языки // Педагогическая ориентация обучения иностранному языку в средней школе. Чебоксары: Чеб. книжное изд-во, 1991. С. 18-29.

2. Исаев Ю.Н., Емельянова М.В., Кузнецова Т.Н. Описание обычаев чувашского народа на немецком языке (на примере поэмы К.В. Ива- 
нова «Нарспи») // Вестник Чувашского университета. 2018. № 4. C. 244-249.

3. Кузнецова Т.Н. Диалекты чувашского языка в переводах произведений немецкой литературы: Сборник научных трудов молодых ученых и специалистов. Чебоксары: Изд-во Чувашск. гос. ун-та, 2018. C. $425-428$.

4. Кузнецова Т.Н. Трукова А.И. Немецкая поэзия: лингвистические и стилистические особенности перевода на чувашский язык // Coвременные исследования социальных проблем. 2017. Т. 9. № 1. С. $136-144$.

5. Латышев Л.К. Технология перевода. М.: Просвещение, 2000. 280 с.

6. Миньяр-Белоручев Р.К. Теория и методы перевода. М.: Московский Лицей, 1996. 298 с.

7. Трукова А.И. Поэтический дискурс и перевод // Вестник Чувашского университета. 2015. № 4. С. 290-294.

8. Яковлева Т.Н. История чувашско-немецкий литературных взаимосвязей // Вестник Чувашского университета. 2010. № 1. С. 253-259.

9. Яковлева Т.Н., Трукова А.И. Народная мудрость в произведении И.В. Гете «Фауст»: особенности перевода // Лингвистика, лингводидактика, переводоведение: актуальные вопросы и перспективы исследования сб. материалов Междунар. науч.-практ. конф., 2014. С. $252-256$.

\section{References}

1. Ivanov V.A. Tragediya «Faust» kak pedagogicheskoe proizvedenie v sopostavlenii ee s perevodami na russkiy i chuvashskiy yazyki [Faust as a pedagogical work in comparison with its translations into Russian and Chuvash]. Pedagogicheskaya orientatsiya obucheniya inostrannomu yazyku $v$ sredney shkole [Pedagogical orientation of teaching a foreign language in secondary school]. Cheboksary: Cheb. knizhnoe izd-vo, 1991. P. 18-29.

2. Isaev Yu.N., Emelianova M.V., Kuznetsova T.N. Opisanie obychaev chuvashskogo naroda nanemetskom yazyke (na primere poemy K.V. Ivanova «Narspi») [Description of the customs of the Chuvash people 
in German (on the example of the poem Narspi by K.V. Ivanov)]. Vestnik Chuvashskogo universiteta, 2018. № 4. P. 244-249.

3. Kuznetsova T.N. Dialekty chuvashskogo yazyka v perevodakh proizvedeniy nemetskoy literatury: Sbornik nauchnykh trudov molodykh uchenykh $i$ spetsialistov [Dialects of the Chuvash language in translations of German literature: Collection of scientific works of young scientists and specialists]. Cheboksary: Izd-vo Chuvashsk. gos. un-ta, 2018. P. 425-428.

4. Kuznetsova T.N. Trukova A.I. Nemetskaya poeziya: lingvisticheskie i stilisticheskie osobennosti perevoda na chuvashskiy yazyk [German poetry: linguistic and stylistic features of translation into the Chuvash language]. Sovremennye issledovaniya sotsial'nykh problem. 2017. V. 9. № 1. P. 136-144.

5. Latyshev L.K. Tekhnologiya perevoda [Translation technology]. Moscow: Prosveshchenie, 2000. 280 p.

6. Min'yar-Beloruchev R.K. Teoriya i metody perevoda [Theory and methods of translation]. Moscow: Moskovskiy Litsey, 1996. 298 p.

7. Trukova A.I. Poeticheskiy diskurs i perevod [Poetic discourse and translation]. Vestnik Chuvashskogo universiteta. 2015. № 4. P. 290 294.

8. Yakovleva T.N. Istoriya chuvashsko-nemetskiy literaturnykh vzaimosvyazey [The history of the Chuvash-German literary interrelations]. Vestnik Chuvashskogo universiteta. 2010. № 1. P. 253-259.

9. Yakovleva T.N. Trukova A.I. Narodnaya mudrost' v proizvedenii I.V. Gete «Faust»: osobennosti perevoda [Folk wisdom in the work Faust by J. Goethe: translation peculiarities]. Lingvistika, lingvodidaktika, perevodovedenie: aktual'nye voprosy i perspektivy issledovaniya sb. materialov Mezhdunar. nauch.-prakt. konf., 2014 [Linguistics, linguodidactics, translation studies: topical issues and research prospects collection. materials Intern. scientific-practical conf.]. P. 252-256.

\section{ДАННЫЕ ОБ АВТОРАХ}

Емельянова Маргарита Валентиновна, кандидат филологических наук, декан факультета иностранных языков 
Чувашский государственный университет им. И.Н. Ульянова пр. Московский, 15, г. Чебоксары, Российская Федерация marg_emel@yahoo.com

Кузнецова Татьяна Николаевна, кандидат филологических наук, доцент кафедры иностранных языков №1 Чувашский государственньй университет им. И.Н. Ульянова пр. Московский, 15, г. Чебоксары, Российская Федерация elre2007@mail.ru

\section{DATA ABOUT THE AUTORS}

Emelianova Margarita Valentinovna, Candidate of Philological Sciences, Dean, Foreign Languages Department Chuvash State University named after I.N. Ulyanov 15, Moskovski ave., Cheboksary, Russian Federation marg_emel@yahoo.com

Kuznetsova Tatiana Nikolaevna, Candidate of Philological Sciences, Associate Professor, Foreign Languages Department № 1 Chuvash State University named after I.N. Ulyanov 15, Moskovski ave., Cheboksary, Russian Federation elre2007@mail.ru 